\title{
PERANCANGAN DAN IMPLEMENTASI E-COMMERCE UNTUK PENJUALAN BAJU ONLINE BERBASIS ANDROID
}

\author{
Abdi Pandu Kusuma'), Kurniawan Agus Prasetya ${ }^{2)}$ \\ 1), 2) Program Studi Teknik Informatika - Fakultas Teknologi Informasi, \\ Universitas Islam Balitar, Blitar \\ ${ }^{1)} e$-mail:pans.uib1blitar@gmail.com, ${ }^{2}$ e-mail:agusk2874@ @mail.com
}

\begin{abstract}
Abstrak: Saat ini aplikasi berbasis mobile telah banyak digunakan seiring semakin mudahnya perangkat smartphone. Sering dengan hal tersebut, maka banyak aplikasi yang dikembangkan dan dapat diunduh oleh pengguna melalui smartphone. $C V$. Cahaya Mandiri adalah grosir yang menjual beberapa pakaian. CV. Cahaya Mandiri masih melakukan promosi dan penjualan melalui website dan sosial media, sehingga jangkauan promosi dan penjualan masih terbatas dan belum bisa meluas kebeberapa daerah. Pada penelitian ini dilakukan untuk perancangan dan pembangunan aplikasi berbasis mobile serta pengujian dengan menggunakan metode white box. Metode ini diimplementasikan e-commerce ke dalam sebuah aplikasi penjualan baju berbasis mobile. Pengumpulan datanya menggunakan observasi, studi pustaka dan wawancara. Kemudian data diimplementasi untuk dapat diaplikasikan pada aplikasi mobile. Pengimplementasian aplikasi berbasis mobile ini dirancang menggunakan bahasa pemrograman Java dengan aplikasi pendukung android studio versi 1.51. Hasil pengujian menggunakan metode white box untuk menguji software mengetahui cara kerja suatu perangkat lunak secara internal dapat diketahui bahwa metode white box.

Kata Kunci : Aplikasi, android, whitebox, smartphone, mobile.
\end{abstract}

\section{Pendahuluan}

Penggunaan teknologi diharapkan dapat memberikan manfaat yang besar terhadap dunia bisnis yang kompetitif tersebut. Perusahaan yang mampu bersaing dalam kompetisi tersebut adalah perusahaan yang mampu mengimplementasikan teknologi ke dalam perusahannya.

Salah satu jenis implementasi teknologi dalam hal meningkatkan persaingan bisnis adalah dengan menggunakan electronic commerce (E-commerce), yaitu untuk memasarkan berbagai macam produk atau jasa, baik dalam bentuk fisik maupun digital. Dengan ini E-commerce didefinisikan sebagai proses pembelian dan penjualan antara dua belah pihak di dalam suatu perusahaan dengan adanya pertukaran barang, jasa, atau informasi melalui media internet.

\section{a. Android}

\section{Tinjauan Pustaka}

Android merupakan (Putra,2012) sistem operasi mobile yang tumbuh di tengah sistem operasi lainnya yang sedang berkembang dewasa ini. Sistem operasi lainnya 
seperti windows Mobile, IOS, Symbian, dan masih banyak lagi juga menawarkan kekayaan isi dan keoptimalan berjalan di atas perangkat keras (hardware) yang ada. Akan tetapi, sistem operasi yang ada ini berjalan dengan memprioritaskan aplikasi inti yang dibangun sendiri tanpa melihat potensi yang cukup besar dari aplikasi pihak ketiga.

\section{b. JSON}

Java Script Object Notation, (Alatas, 2014) adalah kodingan terbuka yang didesain untuk membaca data interchange. JSON ini berasal dari Bahasa scripting JavaScript yang gunanya mempresentasikan struktur data sederhana dan array asosiatif, yang sering disebut objek. Meskipun sering dihubungkan dengan JavaScript, JSON adalah Bahasa pemrograman independen, dengan parser yang tersedia untuk banyak Bahasa pemrograman. Fortmat JSON awalnya diklasifikasikan oleh Douglas CrockFord, dan dijelaskan dalam RFC 4627 (Sebuah Standarisasi International).

\section{c. UML}

Unified Modeling Language (UML) adalah merupakan sistem arsitektur yang berjalan dalam OOAD (object-Oriented Analysis Design) dengan satu Bahasa yang konsistensi untuk menentukan, visualisasi, mengkontruksi dan mendokumentasi artifact (sepotong informasi yang digunakan atau dihasilkan dalam suatu proses rekayasa software, dapat berupa model, deskripsi, atau software) yang terdapat dalam sistem software.

\section{d. Internet}

Internet atau "Interconnected Networking" merupakan sebuah jaringan komputer yang saling berhubungan dari satu komputer dengan komputer lainnya, sehingga terbentuklah sebuah jaringan komputer secara luas di seluruh dunia yang dapat saling berkomunikasi, berinteraksi, bertukar informasi atau tukar-menukar data (Humdiana dan Indrayani, 2005).

\section{e. Metode White Box}

Pengujian WhiteBox (Ayuliana, 2009) adalah metode desain test case yang menggunakan struktur control desain procedural untuk memperoleh test case. Jika ada modul yang menghasilkan output yang tidak sesuai dengan proses bisnis yang dilakukan, maka baris-baris program, variabel, dan parameter yang terlibat pada unit tersebut akan dicek satu persatu dan diperbaiki, kemudian di-compile ulang. Pengujian whitebox bisa dilakukan dengan pengujian basis path, metode ini merupakan salah satu teknik pengujian struktur control untuk menjamin semua statemen dalam setiap jalur independen program dieksekusi minimal 1 kali. Pengujian menggunakan metode White Box dapat diimplementasikan menggunakan Notasi Diagram Alir (Path Graph Notation). Notasi yang digunakan untuk menggambarkan jalur eksekusi adalah notasi diagram alir (atau grafik program), yang menggunakan notasi lingkaran (simpul atau node) dan anak panah (link atau edge) (Ayuliana, 2009). Notasi ini menggambarkan aliran control logika yang digunakan 
dalam suatu Bahasa pemrograman. Notasi diagram tersebut ditunjukkan pada tabel 1 (sumber Ayuliana, 2009):
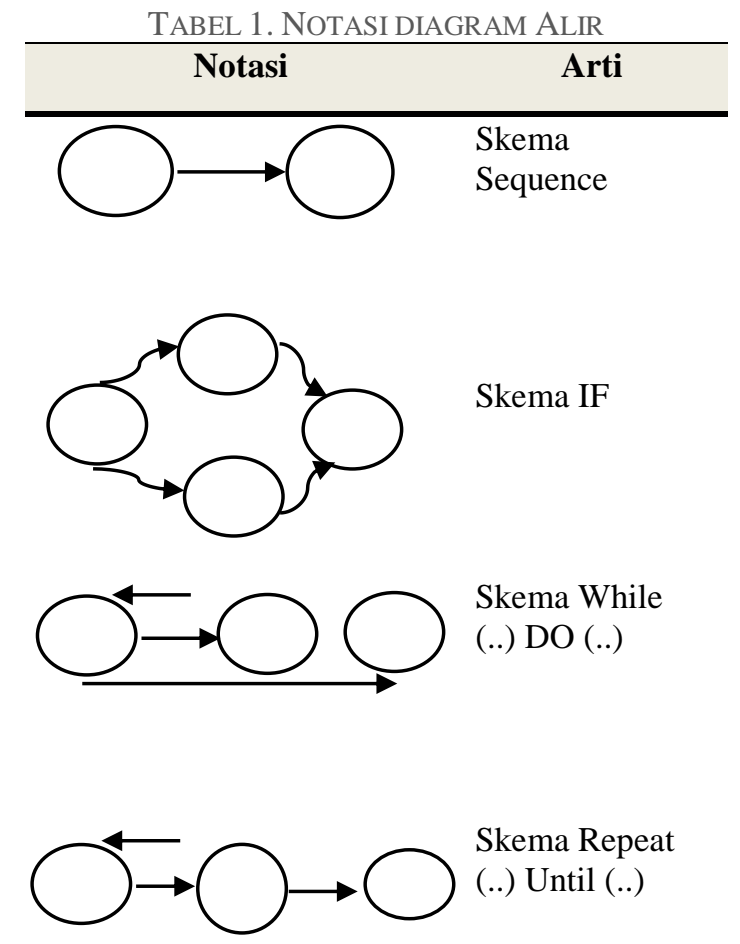

Skema Repeat

(..) Until (..)

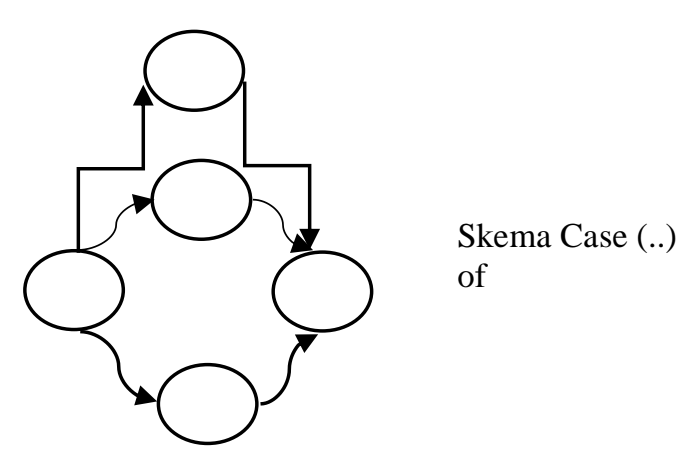

\section{f. Data Flow Diagram (DFD)}

Data flow diagram (Nimas, 2016) adalah alat pembuatan model yang memungkinkan professional sistem untuk menggambarkan sistem sebagai suatu jaringan proses fungsional yang dihubungkan satu sama lain dengan alur data, baik 
secara manual maupun komputerisasi.. Simbol-simbol dalam DFD ditunjukkan pada Tabel 2 (sumber: Albahra, 2005).

\begin{tabular}{|c|c|c|c|}
\hline No & simbol & Nama & Keterangan \\
\hline $\mathbf{1}$ & & $\begin{array}{l}\text { Proses } \\
\text { Transforma } \\
\text { si }\end{array}$ & $\begin{array}{l}\text { Proses yang } \\
\text { mengubah } \\
\text { data dari input } \\
\text { menjadi } \\
\text { output. }\end{array}$ \\
\hline 2 & & $\begin{array}{l}\text { Sumber \& } \\
\text { Tujuan } \\
\text { Data }\end{array}$ & $\begin{array}{l}\text { Karyawan dan } \\
\text { organisasi } \\
\text { yang } \\
\text { mengirim data } \\
\text { dan menerima } \\
\text { data dari } \\
\text { sistem. }\end{array}$ \\
\hline 3 & & Arus Data & $\begin{array}{l}\text { Arus data } \\
\text { yang masuk ke } \\
\text { dalam dan luar } \\
\text { dari sebuah } \\
\text { proses. }\end{array}$ \\
\hline 4 & & $\begin{array}{l}\text { Penyimpan } \\
\text { Data }\end{array}$ & $\begin{array}{l}\text { Penyimpan } \\
\text { data. }\end{array}$ \\
\hline
\end{tabular}

III. Perancangan Dan Implementasi Sistem

\section{a. Perancangan Proses Menggunakan DFD Level 0}

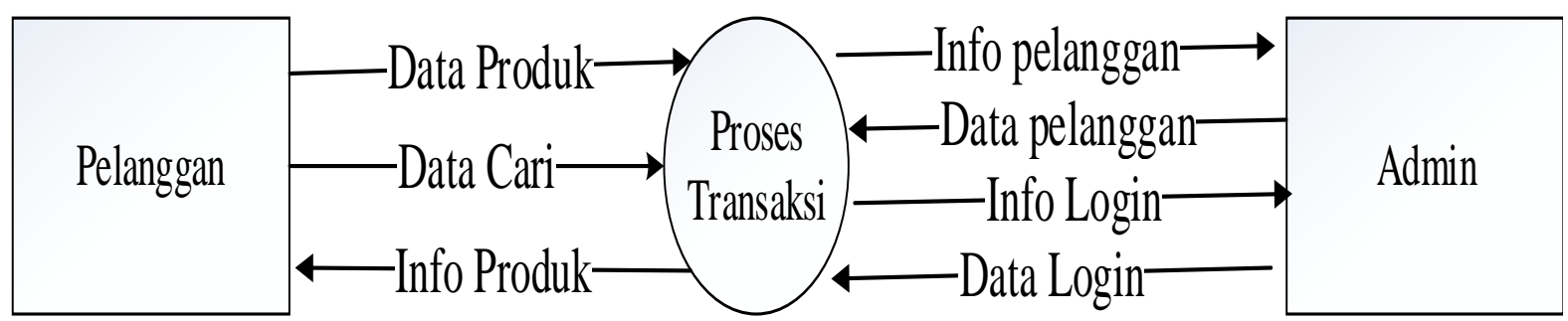

Gambar 1 DFD level 0

Pada gambar 1 untuk DFD level 0 pelanggan dapat memasukkan data pelanggan untuk diproses admin, pelanggan dapat informasi produk produk baju yang ingin dipesan diproses transaki menjadi informasi dan dikelola admin. 


\section{b. Perancangan Proses Menggunakan DFD level 1}

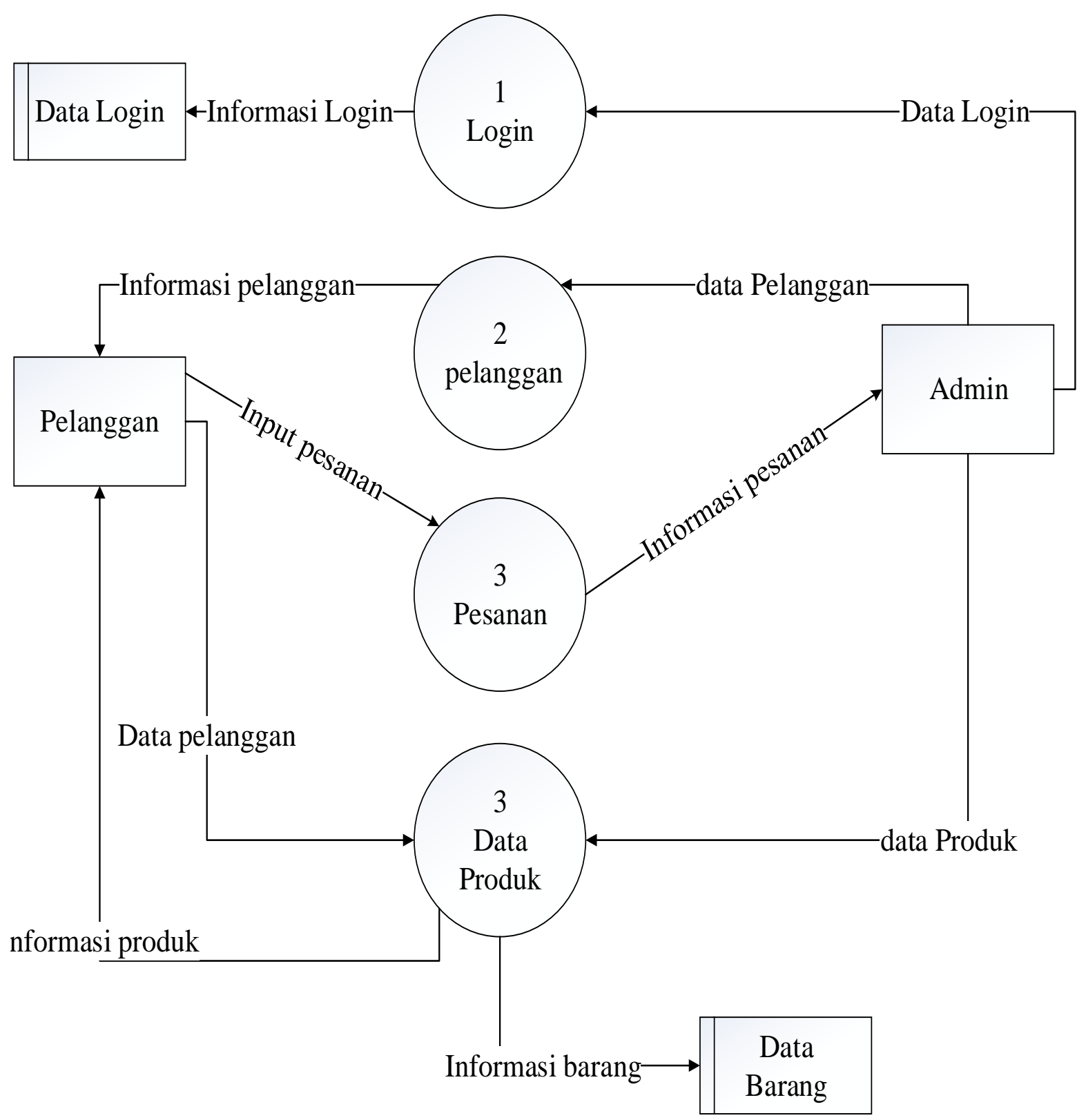

Gambar 2 DFD level 1

Pada gambar 2 pelanggan bisa login, memesan, barang dan memilih produk yang ingin dibeli selanjutnya data pelanggan dan produk disimpan didalam data base selanjutnya admin bisa mengelola data pelanggan, pesanan dan produk baju. 


\section{c. Perancangan Proses Menggunakan Use case Diagram}

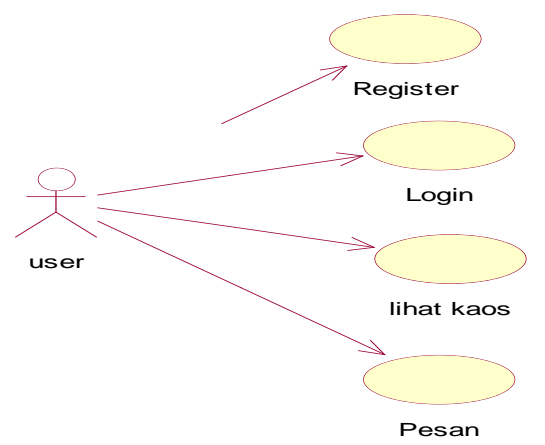

Gambar 3 use case diagram aplikasi safaraz

Gambar 3 dijelaskan use case masing-masing actor, yaitu: Aktor user dapat melakukan lihat kaos dan mencari produk yang ingin dibeli actor admin bisa login mengelola data kaos menambah produk jenis terbaru, bisa mengedit barang dan menghapus produk lalu juga bisa mengelola user.

\section{d. $\operatorname{ERD(Entity~Relationship~Diagram)~}$}

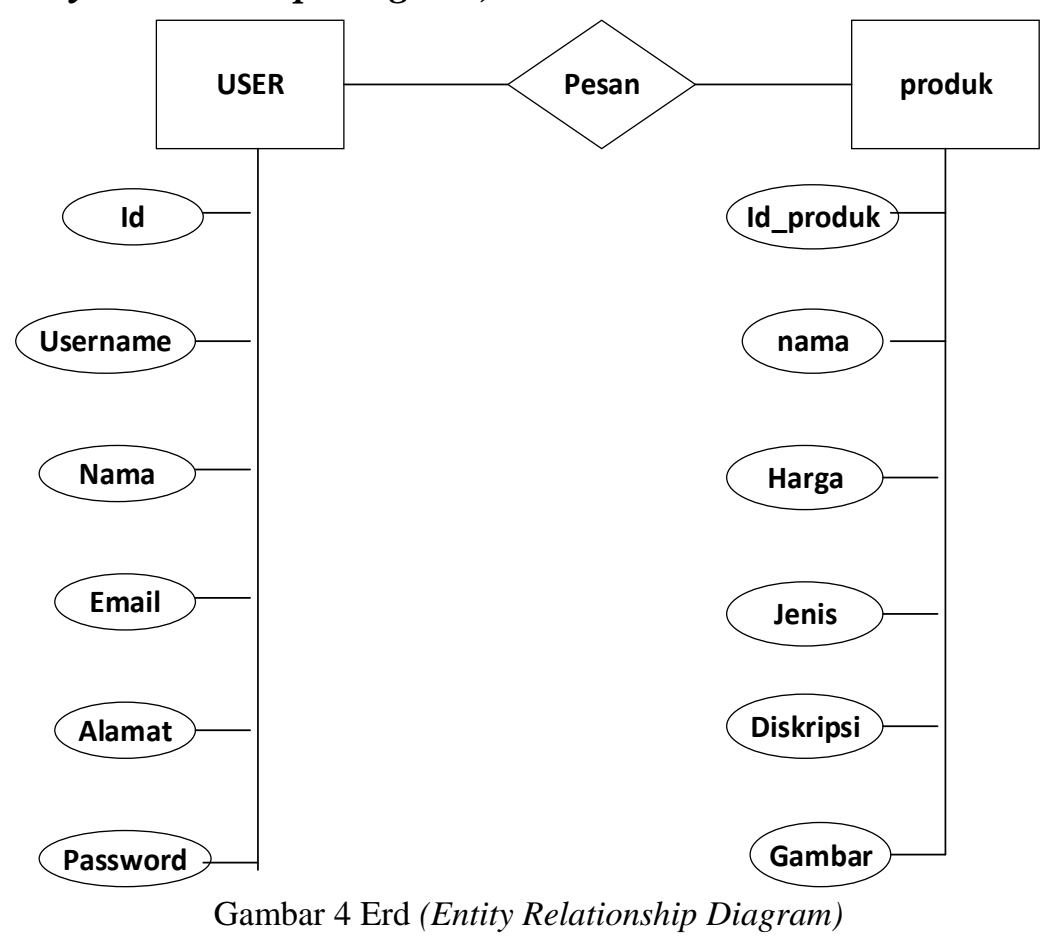

Gambar 4 diatas ditampilkan erd dari aplikasi safaraz, dalam user memiliki entity id, username, nama, email, alamat, dan password sedangkan produk terdapat id_produk, nama, harga, jenis, diskripsi dan gambar. 


\section{e. Implementasi Sistem}

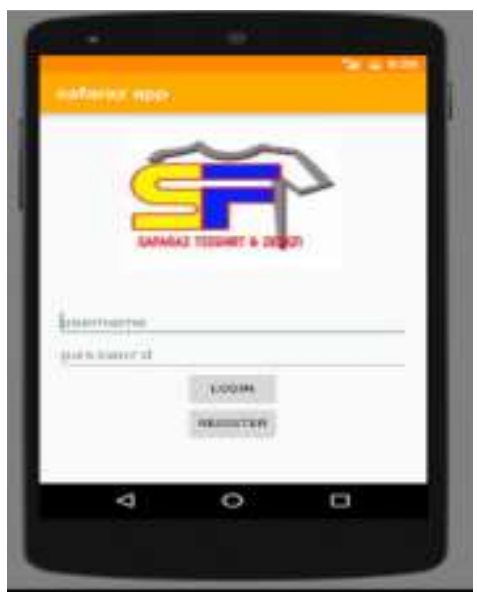

Gambar 5 Halaman Login

\section{f. Bagan alir Aplikasi Safaraz}

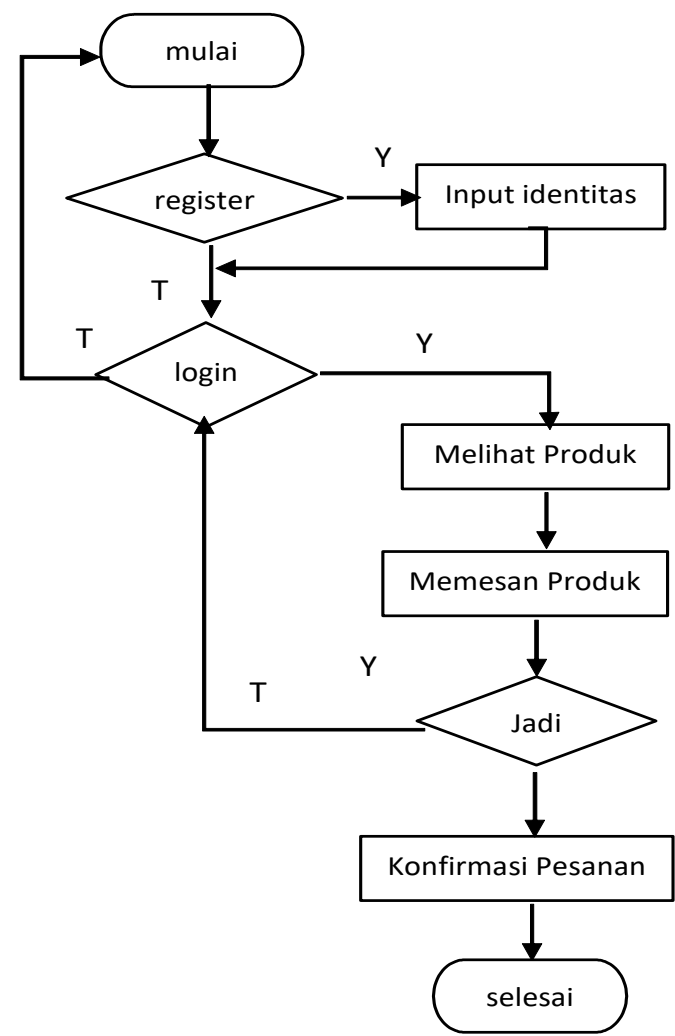

Gambar 6 Bagan Alir

Pengguna (user) harus daftar (register) terlebih dahulu memasukkan identitas username, nama, email, alamat, dan password. Jika sudah terdaftar menjadi member aplikasi safaraz silahkan login dengan memasukkan username dan password yang sudah terdaftar setelah itu akan masuk pada halaman home aplikasi. Selanjutnya 
pengguna bisa melihat produk baju kaos polo dan kaos polos. Kemudian pengguna bila ingin memesan produk/membeli bisa melihat jika pelanggan jadi memesan produk maka harus mengirimkan bukti transfer dari bank. Jika tidak jadi membeli produk pelanggan akan kembali login dan melohat produk baju. Cara pemesanan setelah transfer uang ke nomer rekening atm, admin akan mengirim konfirmasi pesanan ke pelanggan.

\section{g. Flow Graph Login}

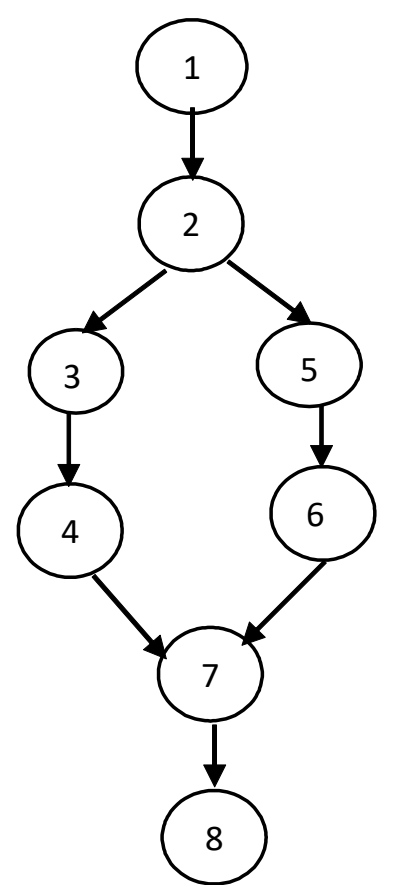

Gambar 7 Flow graph login

Gambar 7 ditampilkan flow graph dari program login aplikasi safaraz. Dari gambar 7 maka dapat ditentukan flow graph program login sebagai berikut:

1. Method Private onlogin

Memanggil method login

2. Parameter username password

Untuk menginput variable username dan password

3. New respon listener

Untuk memproses username dan password

4. Onresppon usermodel

Proses untuk mengakses user/pengguna

5. Kondisi listenenr eror

Jika username dan password salah

6. Jika username dan password benar

Bisa masuk ke aplikasi menu home 


\section{Request}

Untuk meminta data dari database safaraz

8. End

Selesai

\section{h. Kompleksitas Siklomatis (Cyclomatic Complexity)}

Cyclomatic Complexity merupakan suatu sistem pengukuran yang menyediakan ukuran kuantitatif dari kompleksitas logika suatu program. Pada Basis Path Testing, hasil dari cyclomatic complexity digunakan untuk menentukan banyaknya independent paths. Independent path adalah sebuah kondisi pada program yang menghubungkan node awal dengan node akhir.

Pemodelan ke dalam flow graph yang telah dilalakukan terhadap algoritma tersebut menghasilkan jumlah kompleksitas siklomatis (cyclomatic complexity) melalui persamaan $\quad \mathrm{V}(\mathrm{G})=\mathrm{E}-\mathrm{N}+2$, dimana $\mathrm{V}(\mathrm{G})$ merupakan jumlah kompleksitas siklomatis, E merupakan sisi atau edge (garis penghubung antar node) dan $\mathrm{N}$ merupakan jumlah simpul node.

$\mathrm{V}(\mathrm{G})=2$

$\mathrm{V}(\mathrm{G})=\mathrm{E}-\mathrm{N}+2$

$\mathrm{V}(\mathrm{G})=\mathrm{P}+1$

Keterangan:

$\mathrm{V}(\mathrm{G})=$ grafik alur

$\mathrm{E}=$ jumlah edge (tanda panah)

$\mathrm{N}=$ jumlah node (lingkaran)

$\mathrm{P}=$ Predicate nodes (cabang)

Dengan menggunakan rumus cyclomatic complexity metric dapat dihitung nilai kompleksitas dari program yang akan diuji. Berikut perhitungannya:

$\mathrm{V}(\mathrm{G})=2$

$\mathrm{V}(\mathrm{G})=\mathrm{E}-\mathrm{N}+2=8-8+2=2$

$\mathrm{V}(\mathrm{G})=1+1=2$

Hasil nilai kompleksitas adalah 2.

\section{i. Jalur Independent (Independent Path)}

Jalur independent adalah jalur yang terdapat dalam program yang memperkenalkan kumpulan perintah pemrosesan atau kondisi baru. Jadi cyclomatic complexity untuk gambar 4.12 adalah 2 . Berdasarkan cyclomatic complexity tersebut, maka terdapat 2 jalur (path) yang terdiri dari :

Jalur $1=1-2-3-4-7-8$

Jalur $2=1-2-5-6-7-8$

Penentuan kasus uji untuk jalur independent tersebut dan hasil eksekusinya dijelaskan pada tabel 3 .

TABEL 3. HASIL JALUR INDEPENDENT 


\begin{tabular}{clllc}
\hline Jalur & \multicolumn{1}{c}{ Kasus Uji } & Hasil yang diharap & Hasil yang didapat & Hasil \\
\hline 1 & $\begin{array}{l}\text { Memberi atribut username dan } \\
\text { password dengan data yang } \\
\text { sudah berbeda dengan yang ada } \\
\text { didatabase. }\end{array}$ & $\begin{array}{l}\text { Method akan berhenti } \\
\text { dan akan menampilkan } \\
\text { pesan }\end{array}$ & $\begin{array}{l}\text { Proses akan terhenti dan } \\
\text { menampilkan pesan }\end{array}$ & Ok \\
2 & $\begin{array}{l}\text { Memberi nilai atribut username } \\
\text { dan password dengan data yang } \\
\text { sudah ada didatabase. }\end{array}$ & $\begin{array}{l}\text { Method akan } \\
\text { menjalankan activity } \\
\text { login }\end{array}$ & $\begin{array}{l}\text { Method akan } \\
\text { menjalankan activity } \\
\text { login }\end{array}$ & Ok \\
\hline
\end{tabular}

\section{j. Pengujian Tampilan}

Setelah program diberikan kepada user (pengguna), program bisa dijalankan atau tidak. Metode ini biasa digunakan dengan menggunakan tabel referensi masukkan dan keluaran untuk menguji perilaku sistem saat diberikan masukkan tertentu.Berikut ini hasil pengujian tampilan pada tabel 4 .

\begin{tabular}{cccc}
\multicolumn{4}{c}{ Tabel 4 Pengujian Tampilan } \\
\hline No & Input & Output & Hasil \\
\hline 1 & Klik Button Register & Register Berhasil & Sesuai \\
2 & Klik Button Login & Muncul Halaman Home & Sesuai \\
3 & Klik Button pemesanan & Muncul Cara Pesanan & Sesuai \\
\hline
\end{tabular}

\section{k. Hasil Penghitungan Angket Kepuasan Pelanggan}

Prosentase perhitungan penentuan pada penilaianmeudah untuk menggunakan metode white box berdasarkan angket pelanggan dapat ditentukan berdasarkan persamaan 4.4 berikut:

$$
\begin{aligned}
& M=\frac{\text { jumlah pilihan }}{\text { jumlah angket }} \times 100 \% \\
& M=\frac{18}{25} \times 100 \% \\
& M=0.72 \times 100=72 \%
\end{aligned}
$$

Adapaun perhitungan nilai rata-rata pengujian white box dapat ditujukan berdasarkan persamaan berikut:

$$
\begin{aligned}
& M=\frac{\text { hasil pengujian white box }}{4} \\
& M=\frac{280}{4}=70 \%
\end{aligned}
$$

\section{KeSIMPULAN}

Kesimpulan yang didapat setelah proses penelitan, pengujian dan implementasi aplikasi e-commerce berbasis android CV. Cahaya Mandiri sebagai berikut: 
1. Berdasarkan pengujian metode whitebox pada pembahasan diperoleh hasil kepuasan pelanggan sistem e-commerce penjualan baju sebesar $70 \%$.

2. Berdasarkan pengujian tampilan pada pembahasan diperoleh hasil kepuasan dari pelanggan sistem e-commerce penjualan sebesar $63 \%$.

\section{Daftar Pustaka}

Albahra dkk. 2005. Daftar Simbol DFD.

http://elib.unikom.ac.id/files/disk1/455/jbptunikompp-gdl-afriscanim-22749-

5-unikom_a-l.pdf. 1 Juni 2016.

Ayuliana. 2009. Testing dan Implementasi.

http://ayuliana_st.staff.gunadarma.ac.id/Downloads/files/25114/Pertemuan+0

4+-+\%28Software+Testing+Techniques\%29.pdf. 1 Juni 2016.

Iyas. 2011. Implementasi Sistem Penjualan Online Berbasis E-Commerce Pada Usaha

Rumahan GriyaUnik Wanita. Skripsi. Naskah Publikasi. Jakarta: Universitas

Islam Negeri Syarif Hidayatullah.

Mahyudanil, Novri Asyara. 2014. Rancang Bangun Mobile Commerce Berbasis

Android Smartphone dengan Extreme Programming Studi Kasus PT GBI.

Skripsi. Naskah Publikasi. Jakarta: Universitas Islam Negeri Syarif Hidayatullah Jakarta.

Maulana, Shabur Miftah, Heru Susilo dan Riyadi. 2015. Implementasi E-commerce Sebagai Media Penjualan Online (Studi Kasus Pada Toko Pastbrik Kota Malang). Jurnal Administrasi Bisnis. Vol 29: No 1, hal 1-8.

Meimaharani, Rizkysari, dan Diana Laily. 2014. E-Commerce Goody Bag Spund

Bond Menggunakan QR Code Berbasis Web Resposif.Jurnal Simetris. Vol 5

No.2: hal 127-135.

Nugroho, A. (2006). Ecommerce, memahami perdagangan modern di dunia nyata. Bandung:

Informatika.

Putra, Acmad Gazza dkk. 2012. Rancang angun Aplikasi Android Virtual Shopping Berbasis QR Code dan Global Positioning Sistem Untuk User Bergerak. Jurnal Teknik Pomits. Vol.1: hal 1-5.

Putra, Muhammad Iqbal Merdeka Eka. 2012. Aplikasi Ponsel Berbasis Android Untuk Penjualan Pada Kios Eceran Q-Mono Flower. Skirpsi. Naskah Publikasi. Yogyakarta: Sekolah Tinggi Manajemen Informatika dan Komputer.

Satria, Aditya Tegar. 2013. Rancang Bangun Sistem Absensi Karyawan Online Berbasis Web Menggunakan Framework Php Codeigniter \& Mysql (Studi Kasus PT Starone Mitra Telekomunikasi). Jurnal Trasnsit. Vol 1 No 1: hal 53-65. 